\title{
Art and Architecture as Opponents against the Cultural Identity Loss in the Context of a Post-Industrial Environment - The Case of the Manufacturing Villages of Cebolais de Cima and Retaxo, Portugal
}

\author{
By Miguel Ângelo Silva*, Fátima Silva ${ }^{ \pm}$, Marta Roque $^{*}$ \& \\ Álvaro Cidrais ${ }^{+}$
}

\begin{abstract}
Facing the dramatic desertification extent of the territory under study, this article presents the results of an experimental methodology approach on the regeneration of landscapes in the national territory, where man, communities, architecture, art and landscape combine in a visible result, image of synthesis, itself revealing the problem. The deactivation process of the local textile industry, in the territory of Cebolais de Cima and Retaxo, Castelo Branco, Portugal, was marked by a period of stagnation, abandonment and degradation of its manufacturing sites and consequently, of deep degradation of the urban and human landscape. This landscape, which was mainly characterized by an intensive work environment and industrial production, is today essentially portrayed through a legacy of abandoned buildings, materials and machinery, scattered throughout the distorted scenery. It is therefore in a physical, social and human environment with a high rate of abandonment and degradation that matrixes will be found for a process of collaboration between an active group of local forces and the critical mass offered by the University. This was intended to incite a strong awakening of the various agents involved in the alarming conformism installed in these settlements, an environment that transcends the entire frontier territory of the interior border between Portugal and Spain. The beginning of this path with several steps and still in a preliminary stage was offered to students of architecture in Lisbon. It was the opportunity to learn realities other than those of their daily lives, in a universe of excess of information, but weak reflection. It also allowed them to challenge their points of view against the ones of those few who still live in the territory and preferred to stay rather than emigrate as most already did. For this difficult rendezvous, several actions were planned during two years, in Lisbon and Cebolais de Cima and Retaxo, culminating in the so-called Creative Assault, the "occupation" of an abandoned factory intended as a wake-up call for awareness. For three days, various activities and exhibitions took place in this space, inviting the community and local authorities to participate, as well as the students involved in the various moments of work.
\end{abstract}

\section{Introduction}

The heritage (material and immaterial, usually found in an organic and dynamic compound of both dimensions) is a wealth that is carried in our personal culture and shared with a vast network of people with whom we are linked, through our convictions and common principles.

Often, the most essential heritage (or patrimony) is so intimate and imprinted in our essence, that we neither value nor recognize it as such. But it is embedded in

\footnotetext{
*Adjunct Professor, CITAD - Lusíada University, Portugal.

${ }^{ \pm}$CITAD - Lusíada University, Portugal.

${ }^{\ddagger}$ CITAD - Lusíada University, Portugal.

${ }^{+}$CITAD - Lusíada University, Portugal.
} 
buildings, in public spaces, in social (relational) practices, in memories, in writings and ideas, in the systems of exchange that constitute a Place (a geographical space full of memories and emotional meanings, representations and perceptions).

This is how Places are born and evolve, in a continuous process of transformation of communities, from the identities and memories that resulted from the crossing of several civilizations in a certain geographical space (natural and artificial). This is how specific landscapes such as Cebolais de Cima and Retaxo are created.

It is within the context of each Place that public and private spaces, squares and buildings are born, places of worship and production, cultural and social practices, economics and processes of exchange. It is in these Places that communities develop, taking advantage of the assets they have, while they have meaning.

We are dealing with what Augé calls "anthropological places", places that present at least three common characteristics: "identity, relational and historical."

As Augé also points out, the historical qualification of the anthropological place emerges from the moment when, combining identity and relationship, the place is defined by a minimum stability. "It is so to the extent that those who live in it can recognize points of reference that do not have to be objects of knowledge. The anthropological place for them is historical in so far as it escapes history as a science." $" 2$

Thus, in Cebolais de Cima and Retaxo, two parishes now joined, a vast entrepreneurial heritage of textile industrial base was born, and now is dying. It is this heritage that must be re-evaluated and reincarnated in a new paradigm of intervention and development on a territorial basis.

This way, in an increasingly interconnected and global world, we can look at this vast heritage as a wealth (affective and potential) that will transform some factories into production centres of new knowledge and solutions, in a participatory approach that crosses multiple experiences and competences, without recalling the memories of a time long gone.

It is on this basis of thought that the "Lançadeira Project", an entrepreneurial and local development project, gains reason and meaning, becoming a local revitalizer, a catalyst for patrimony and activities that can eventually regenerate the place. We were interested in the confrontation between those who led the territory to what it is today and those who inherited it, and for this the local presence of the Lançadeira's members was central to deepen the knowledge of the local reality and to direct the interaction with some of the actors, survivors of the industrial process. It was with the strong interaction of this local force that alert actions were promoted, designated as "Creative Assault".

By concretizing activities of participative architecture for public spaces and abandoned buildings requalification, it promotes the creative adaptation of the places to a new global socio-economy and can be the trigger for the development of a new economy of collaborative and competitive base.

1. M. Augé, Não Lugares - Introdução a uma antropologia da sobremodernidade (Lisbon: 90 Graus Editions, 2005), 47.

2. Ibid, 48. 


\section{Territorial and Socio-Economic Context}

The present case study is located in the Raia zone at $12.34 \mathrm{~km}$ in a straight line from Spain, belonging to the traditional Beira Baixa province, in the district of Castelo Branco (Figures 1 and 2).

The reason for the origin of the industry in this locality is not well documented to date, but it is speculated that due to the characteristics of its soil, very poor, the textile industry was the only means of subsistence found by this population.

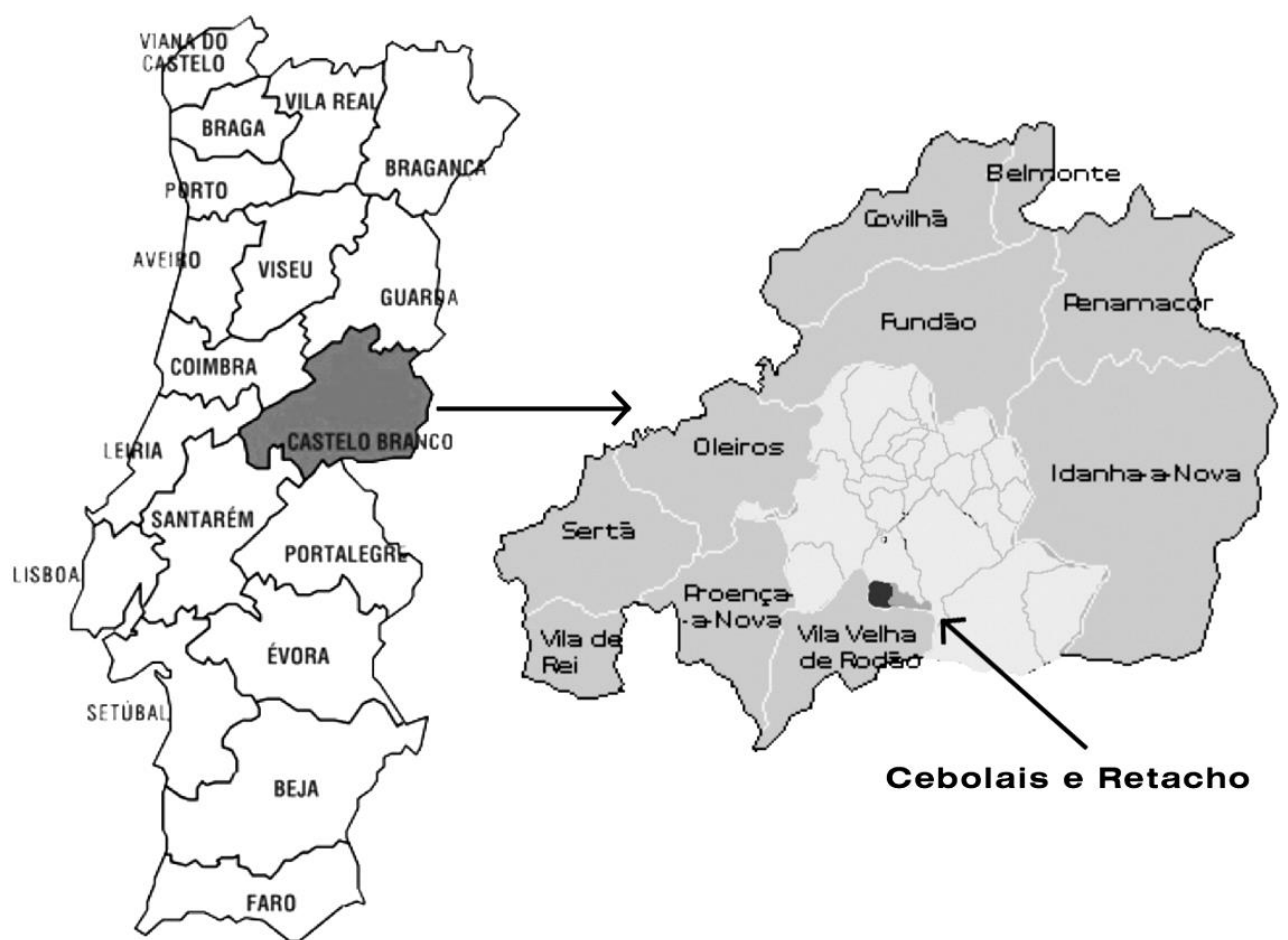

Figure 1. Location of the Territory under Study

Source: Graphics by Marta Roque.

There are documents proving its existence since the beginning of the nineteenth century, "in the Chamber session of September 25, 1809, the collection of 16,000 réis was made by the wool producers of Cebolais and Retaxo."3

In the Inquiry of 1862-1865, related to woollen fabrics, Joaquim Henriques da Silveira, reports that:

"In the parish of Cebolaes de Cima there is an important manufacture of baizes, saragoças, buréis, e xadrezes, ${ }^{4}$ blankets, all of inferior qualities, but of great consumption among the inhabitants of that parish, and in general of the less wealthy classes of diverse towns where their offer arrives. Many hand-drawers,

3. J. R. Cardoso, Subsídios para a história regional da Beira-Baixa-Castelo Branco na sua vida municipal (Junta Provincial da Beira Baixa, 1944), 85.

4. Baizes, saragoças, buréis and xadrezes are varieties of coarse wool fabric. 
seals, and weavers are employed in this industry, working with more than 30 looms."

In the middle of the twentieth century there was a flourishing industry, and it is during the 60s that reached its maximum production exponent, employing about 1,100 direct workers, responsible for $25 \%$ of national carded fabrics through 15 companies and 25 small units of "home industry", that occupied about 18 hectares of territory formed by this parish.

However, this golden age did not last for a long time, with the decline of production starting in 1985 and plunging during the 1990s. Possible causes of this depression include the liberalization of markets, the opening of borders and difficulty in implementing a strategy to respond to the new conditions of competition.

This process of industrialization and its subsequent de-industrialization has caused deep scars in its landscape, being "a register of a society that changes and, if change is so great, so deep and accelerated, there will be signs, not only for a short time and much space to understand or to digest the marks and forms as they are trampling each other, sometimes relics, sometimes wrecks."

The industrial Legacy that characterized the landscape of these two villages in the recent past consists on a set of structures and factory infrastructures that have opportunistically occupied (and still do) this territory of empty spaces integrated in rural parcels. Up to that point, those defined the order and character of that landscape, as well as all products produced, objects connected with production, machines and instruments of manufacture.

The unplanned form of this occupation, and the concentration of a large number of factory buildings, led to a de-characterization of the image of this formerly rural landscape, but were responsible for the development of a culture of identity that promoted economic improvement in this region.

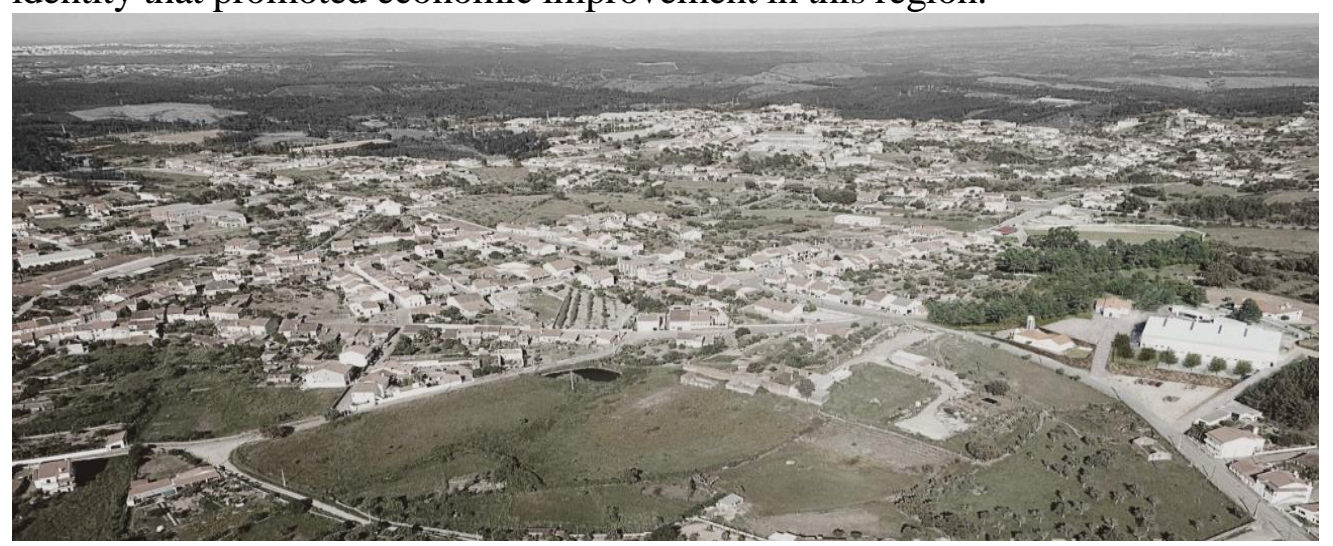

Figure 2. Aerial Photograph of Cebolais de Cima and Retaxo

Source: http://portugalfotografiaaerea.blogspot.pt/2015/01/cebolais-de-cima.html.

5. Á Domingues, Vida no campo (Lisboa: Dafne Editora, 2011), 15. 


\section{From the Idea of Sensorial Landscape}

In this historical and geographical approach we understand the countersense of the idea of installed interiority - however, this is a key territory if we look at its ability for inter-regional and even peninsular articulation, when we consider the new scale of communication and mobility.

For this reason, the more the discussion revolves around the geographical distances in relation to an Atlantic coastline, full of dynamism and actually inaccessible due the lack of a truly efficiently developed transport network, the more important is to capture the qualities and singularities of the place.

The concept of landscape appears from direct subjective observation, by means of sensorial appropriation, of a singular element of the surrounding nature or of a place. It is often an unconscious exchange, but always a reactive, emotional, human one. As Iñaki Uriarte says, "the landscape exists only in the eye of the one who looks at it, and sees it, which attributes aesthetic, pleasant, evocative or cultural qualities. The landscape is the expression of a culture and somehow a compilation of stories, a palimpsest of memory."

Memory is more than just stone walls. The landscape is "only" the end result of man's action, his projection made visible on a larger scale. If one is to understand the intervention in the territory as a process filled of pro-development economic and social objectives, it is crucial to be fully aware of the symbolic values projected by each community. The relationships between disciplines are possibly the most accurate way to integrate and clarify the complexity of the information offered by the modern collective landscape, in the background, the cultural landscape.

This study focuses on the industrial phenomenon, its characterization of a place in the landscape and, analysing at a phase of abandonment and obsolescence of the built legacy still present as a living memory, determines the urgent need to fix the collective culture memory and to re-qualify through resilience. Most likely there won't be a return to the means that previously resulted as productive, but rather it will allows the emergence of new dynamics envisaged for a new global world that still seems strange because incomprehensible or out of control.

\section{Heritage as a Working Tool}

The acknowledgement of a cultural heritage value that justifies the implementation of a museology centre for registration and safeguarding the technical and artistic knowledge of this human capital (the former Corga Factory opened its doors in July 2017 as the Textile Museum of Castelo Branco), is an indicator of the potential legacy present on the site (Figure 3). It is one more part for urban and human regeneration and an opportunity to requalify the landscape from this content of identity. 109.

6. I. Uriarte, Ría de Bilbao: la industria, fábrica del paisaje (Gigon: Abaco/CICEES, 2002), 
The opening of this Museum is a victory for the recognition of the importance of Memory, countering a wave of destruction of many other industries disaffected by European territory, as warns Louis Bergeron,

"You can convince public opinion and local leaders of the interest that an industrial place has as an object of study for the specialist. But it is more difficult that an industrial trace is an object of memory, that concerns all a population and that has a utility both for our contemporaries and for the generations to come." ${ }^{7}$

These villages were revealed throughout the study as having been the setting of an entrepreneurial and pioneering process, in what today can be referred to as Entrepreneurship and Territorial Marketing. In the first half of the twentieth century, someone looked at Cebolais de Cima and Retaxo with this sense of opportunity, capable of promoting the sustainable transformation of that place/territory.

This understanding of place through a regional scale of international vision was the first lesson to be drawn from this study.

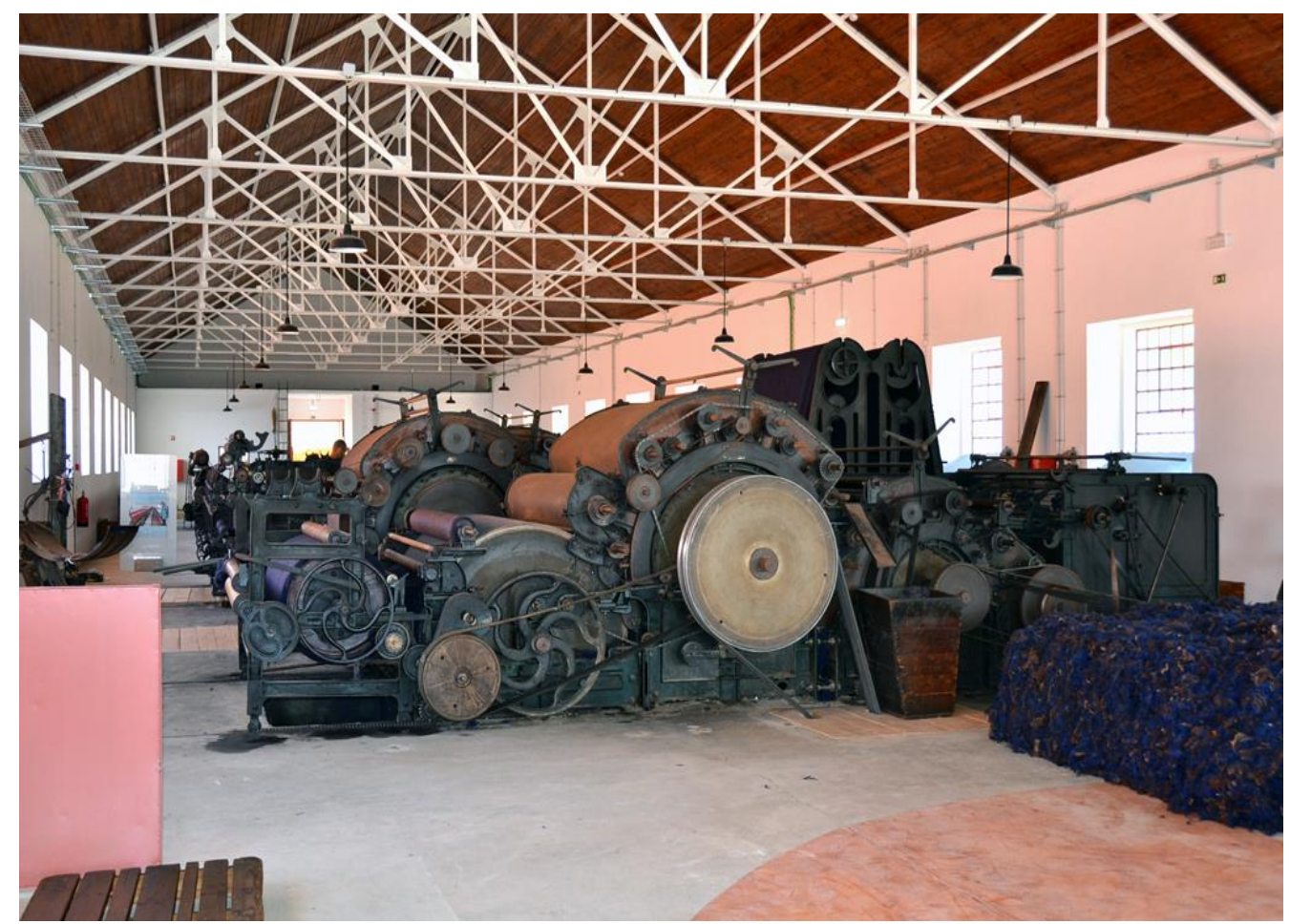

Figure 3. Museum of Textiles of Castelo Branco - MUTEX - Installed in a Building Belonging to an Old Woolen Company - "Carding and Wiring Company of Corga Lda.", Dating from the 1950s

Source: https://www.cmcastelobranco.pt/media/3789/museu_dos_texteis_cebolais_de_cima3.jpg .

7. L. Bergeron, "El patrimonio industrial, qué hacer?" in Patrimonio Industrial: Lugares de la Memoria (Gigon: Incuna, 2002), 11. 
This inheritance is part of the concept of Cultural Landscape, not valid for the edified set but for the material and immaterial archaeological spoliation linked to a textile culture still very present in that physical space, a collective memory and the know-how of the resident population.

"A rural or urban space, an agricultural or industrial landscape, a specific flora or fauna, traditions and knowledges, monuments and archives, meaningful memories, lifestyles only, all belong to the capital of the developing community." 8

It is the collective human values that today can be understood as added value and opportunity for a requalification of the character of the landscape, disqualified by the wild implantation of dispersed industrial nuclei, seeing in this new vision the opportunity of a sustainable regeneration based on a culture of its own.

\section{The Need for Change}

It is at this point that the importance of awareness takes its toll, passing from generation to generation not only the need for its physical maintenance, but essentially the effort of its management.

These roots, this capital, correspond to the inheritance of a community, implying therefore its management. "It is necessary to make them live, to produce, to transform, to remain useful." 9

In most cases, when we revolt against acts of destruction, of different degrees of vandalism on what we recognize as patrimony, that aggression results from the incapacity or inertia on valorising the patrimony, not only for the respect to which is naturally compelled by society but also, ridiculously, because it represents a singular and unique value.

This lack of awareness is more serious as it concerns us, it resonates with our responsibility as actors, performing on our most personal, more intimate heritage, passing through the patrimonies of the local community, of the country or international ones.

It is within this framework that the importance of the past and the role of the industrial tradition in Cebolais de Cima and Retaxo should be highlighted, not as nostalgic figures and as a negation of a dynamic present, but rather by recognizing the importance of belonging to the potential group of foundations of local development.

In this way, it will be possible to recover and revalue the knowledge and assets of three generations of industrial weaver entrepreneurs, while humanizing their lives, counteracting the processes of depopulation, aging and socioeconomic loss of an entire community, of each one of its elements.

It is desired to awaken (and destroy) the ghosts of the announced death of a community, rebuilding new processes of learning, production, exchange and consumption, from the requalification and re-functionalization of the buildings.

8. H. Varine, As raízes do futuro: O patrimônio a serviço do desenvolvimento local (Porto Alegre: Medianiz, 2012), 37.

9. Ibid. 
The poetic feelings unleashed by the abandoned industrial heritage hold enormous potential, in a romantic sensory framework. The telluric power of the great abandoned hangars, among other spaces, has no useful purpose unless they are assigned a role within the panel of actions that a successful revitalization implies.

It is by recognizing the physical and poetic resources of this patrimonial aspect, together with the urban environment in which it is inserted, that we identify its own potential and levels of reutilization.

Whether for tangible or intangible reasons, the alibi for the recycling of industrial heritage rests on the creative exploration of new uses, but this, doing more with less, without colliding with a brutal sweep of memories that such a precious role play in the so-called evolution society.

\section{From the Process of Action}

This process of attention, within a paradigm that recomposes itself, can be substantiated from the dynamization of small (and short) initiatives that, in a continuous and programmed route, produce ephemeral initiatives but with sufficient attraction potential for reflection about people's attachment to the territory.

To Provide scientific and artistic training, carried out by students, designers, craftsmen, anthropologists and architects, focusing on the local community of Castelo Branco and students of various educational levels. They will be the main target audience for the preservation and transmission of knowledge related to the textile heritage and industrial of the parish of Cebolais de Cima and Retaxo with an alternative view. This action aimed to attract attention to the importance of the ethnographic recording of memories, choreographies and materials related to the workmanship, industrial production and artisan work.

Strategies were intersected between traditional and contemporary approaches to weaving, and its appropriation by artists and designers was analogous to a scientific approach based on the reflection on industrial textile heritage and regeneration of urban fabrics.

The interstitial spaces of the rural plots were occupied by large industrial volumes, transforming it from a rural village into an industrial space. From the daily sound of the sirens of the factories to the bustle of the streets, through the noise of the mechanical looms in labour, etc. they all brought new dynamics as well as a new identity to the landscape, although formally, brought those with a negative footprint in terms of planning and the overall image.

This activity is recognized as an economic and cultural asset; implying a population increase and an improvement in the quality of life of the resident population, promoting the development of the place and introducing it into a regional network of the textile culture.

The urgency is evident in the present time, when we arrive at these parishes and we feel the absence of a restlessness youth in the community, especially when we know about its vibrant recent past, little more than a generation or two away. It 
is today, on this time of indifference, that the need for action arises and, as an organized society in which we are inserted, democratic, decentralized, inclusive and more, as adjectives full of positivism, it is important to go beyond, looking into ourselves and detecting true ways to humanize people, organized in communities. By unleashing and engaging in these actions, we also become impregnated, configuring another sense of living for ourselves and those around us.

This experimental operation proposes three moments of approach, diverse in calendar and in depth:

\section{1- Field Class (April 17 and 18, 2015)}

A first moment of contact with the actual reality of the place - a time of auscultation, promoting a reflection based on the first oral reports and visits to factory buildings. This first contact of local drift served as a pretext for an open class held with a group of last-year students of architecture from the Faculty of Architecture of the Lusíada University of Lisbon, who were shuffled to develop regenerative solutions on working groups.

As a final moment, members of the local community were invited, from former bosses, workers and their families, to local political forces, joining in in a truly open-minded presentation, without constraints and, in some cases, with a strong commotion, suggesting the way to the next stage.

\section{2- Architecture Workshop (February 15-20, 2016)}

A second moment of identification/characterization and proposal on a section of this same landscape, with a view to the development of two proposals of intervention on the urban fabric based on the previous regenerative reflections. Program and location were provided by the local authority and students worked on information and data gathered on that landscape reality.

At the same time, a second round of visits accompanied by local testimonies in the first person was promoted.

The places, protagonists of an industrial phenomenon, allowed to witness this archaeological past, as well as the quality of this activity.

The action demonstrates a potential value, contributing to the construction of a visible imaginary, through proposals of requalification of the urban environment.

\section{3- Creative Assault (April 30 to May 3, 2016)}

The third corollary are the most sensitive dilemmas that have been recognized as implicit in this landscape, acting as possible brakes for desertification, as allies to hypothetical solutions patent in a global context based on an entrepreneurial culture of knowledge recycling. 


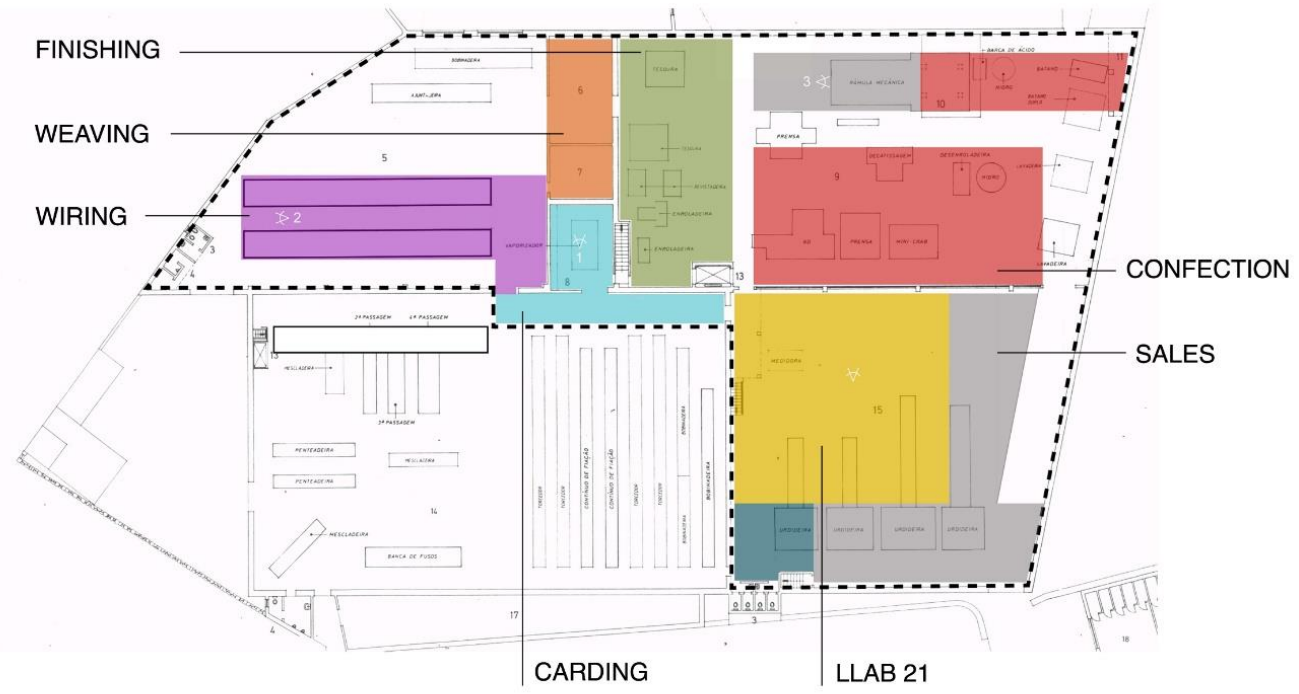

Figure 4. Creative Assault: Zoning Plan of Pereirinho Factory for the "Creative Assault"

Source: Drawing by Marta Roque.

This last action "Creative Assault" or "Lanç'arte" was intended to give back to the population, through the artistic expression in an orderly manner and intentionally contextualized by the genuine scenario of an old factory space, the old Wool Factory Pereirinho, where time was standing still, expectant, providing a moment of decompression and reflection on the industrial past of the present case study; a momentous revival that allowed for more joint reflection and a first opening of paths of continuity. An image of crossed memories with a regional active present, an integrated direct confrontation which brings together the various facets of this landscape: entrepreneurs, workers and families, buildings, infrastructures, machinery, raw materials, products, rhythms and rites, space... every item integrated within a landscape system.

The humanization of the participants can be promoted by art through its transforming character. For this, art must be made accessible to the maximum number of people, enabling people to rebuild themselves through it. The statement attributed to Pablo Picasso in how art is a lie that leads to an understanding of life, to truth, supports us in introducing art as a fundamental element in this process. Art needs to move, to confront different domains or themes. It was not about promoting a cause or trying to educate an audience, as we rely more on successful fruits from informal encounters - for the Portuguese, the best table of meetings is the dining table!

In the operation "Creative Assault", the desire was to occupy different sections of the old industrial unit, many already unrecognizable, such was its deprivation of the mechanical skeleton that once gave its meaning. Using each of these spaces to look at time, past, present and future, we were distanced from the warning paper we wanted to see printed. 


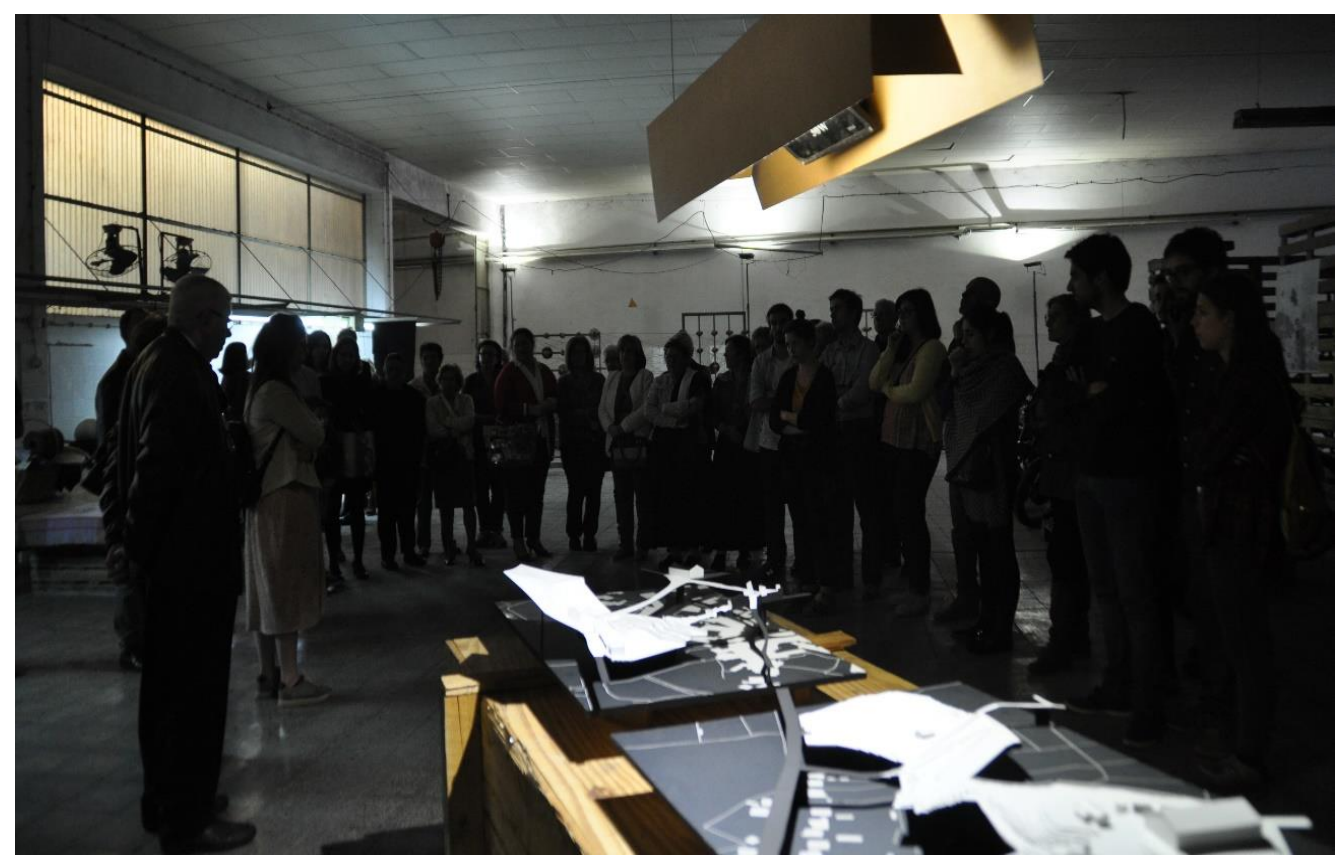

Figure 5. Creative Assault: Presenting Proposals of the Architecture Workshop Source: Photo by Miguel Angelo Silva.

The basic concept behind the action of the Assault was the installation of several facilities that were part of a dialogue with the very specific environment of the old factory (Figure 4).

For the working group, the assembly of a set of plastic effect elements in conjunction with sound and visual installations ${ }^{10}$ was the means of igniting a situation that we wanted to be felt unequivocally as a provocative one. The place and its context go much further than the materials used in the various installations assembled, since they are actually its subject. We were facing a deserted industrial place, violated and emptied of machines and workers. The significance of these remains, what we experience as we cross the empty space, was questioned to transform their perception.

In the preparatory work, we got a sense of the functions previously exercised in the various spaces, their memory and their atmospheres. It was not a specific or specialized approach - as, for example, if one were to read only from the architectural point of view or as a case of industrial heritage tout court - but an overall view. We sought to understand space as a whole, even when we chose to isolate a certain element, to explore a particular volume, or to limit or release the visitor's/participant's range of vision (Figures 5-7).

10. The responsibility of light and sound installations belongs to the Research Center of Light of CITAD, Prof. Arq. Samuel Roda Fernandes and Dra. Patrícia Freire. The pieces of video and sound were written by Ricardo Rezende. 


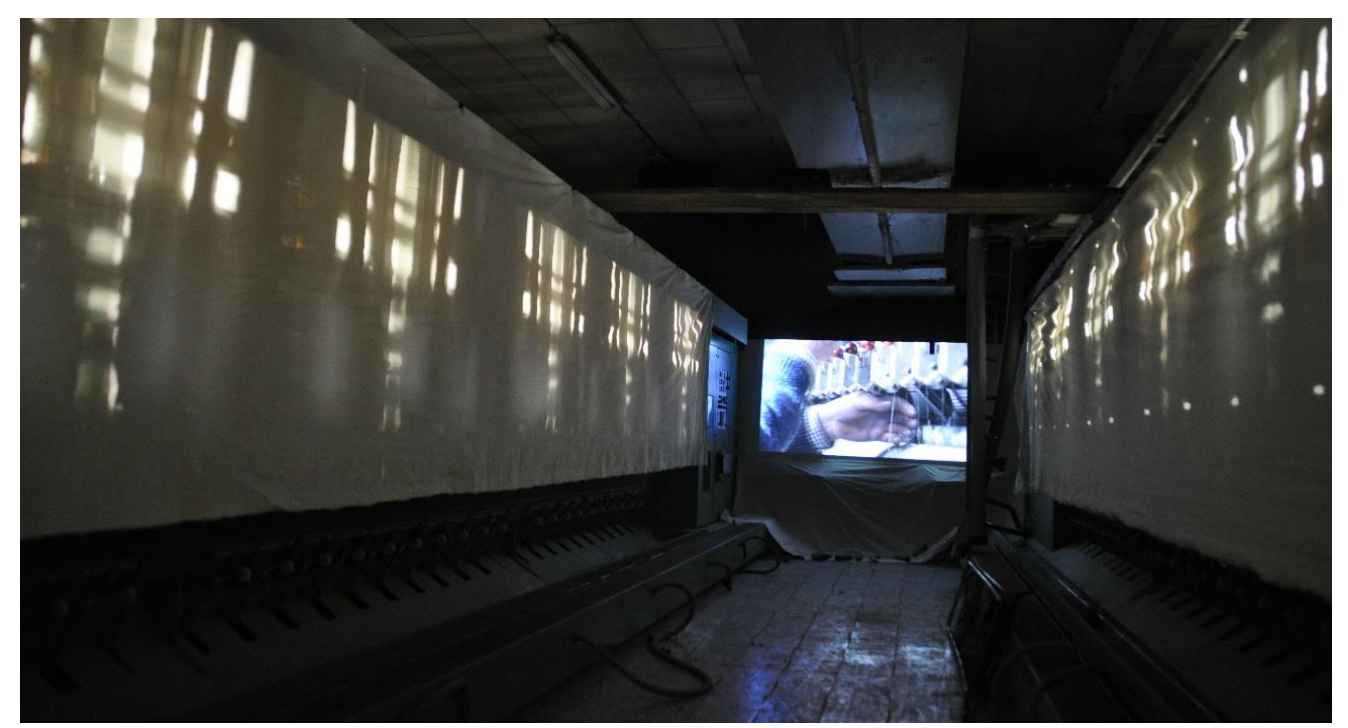

Figure 6. Creative Assault: Installation of Video and Light in the Wiring Continuous

Source: Photo by Miguel Angelo Silva.

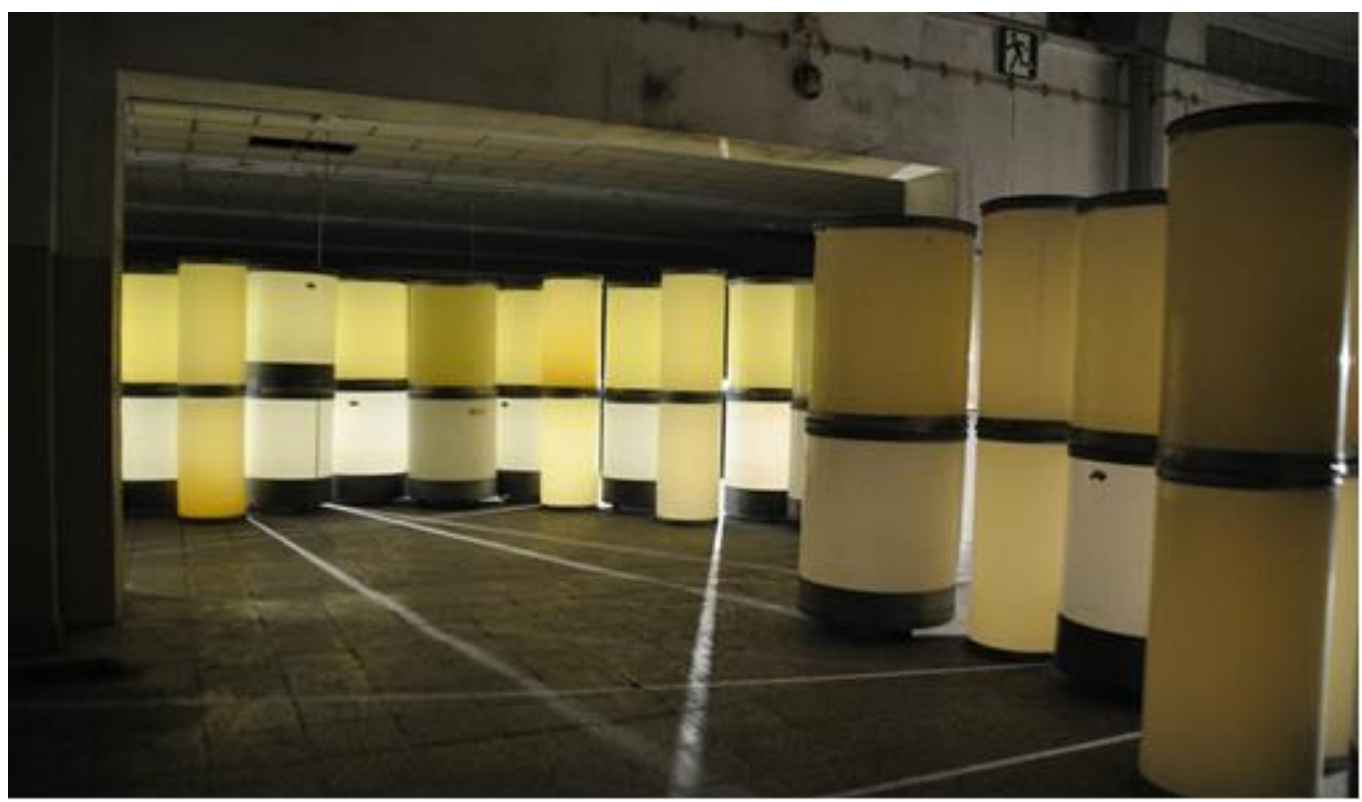

Figure 7. Creative Assault: Light Installation

Source: Photo by Miguel Angelo Silva. 


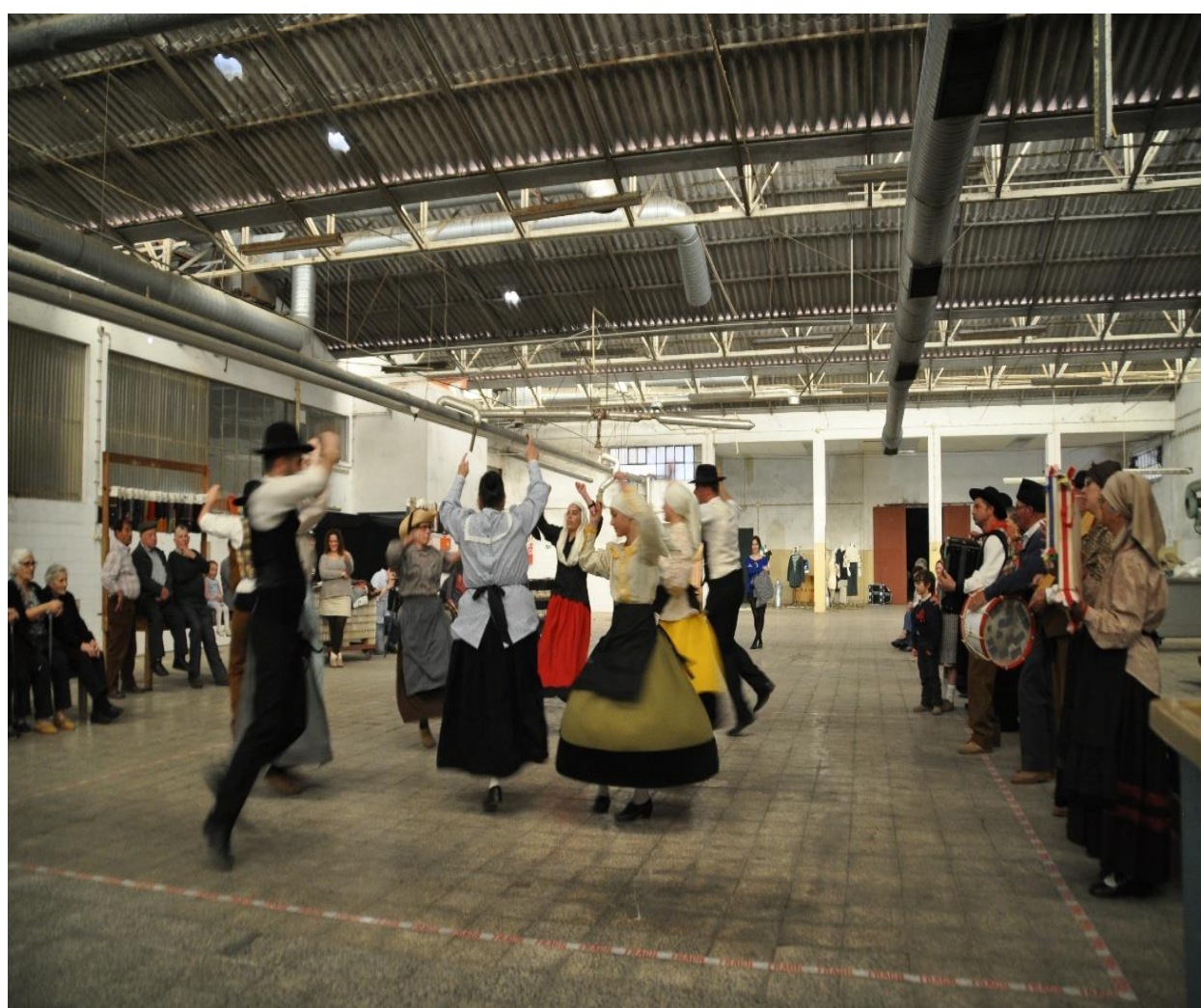

Figure 8. Creative Assault: Overview of the Occupation of Fábrica Pereirinho - Local Group of Folk Dances

Source: Photo by Miguel Angelo Silva.

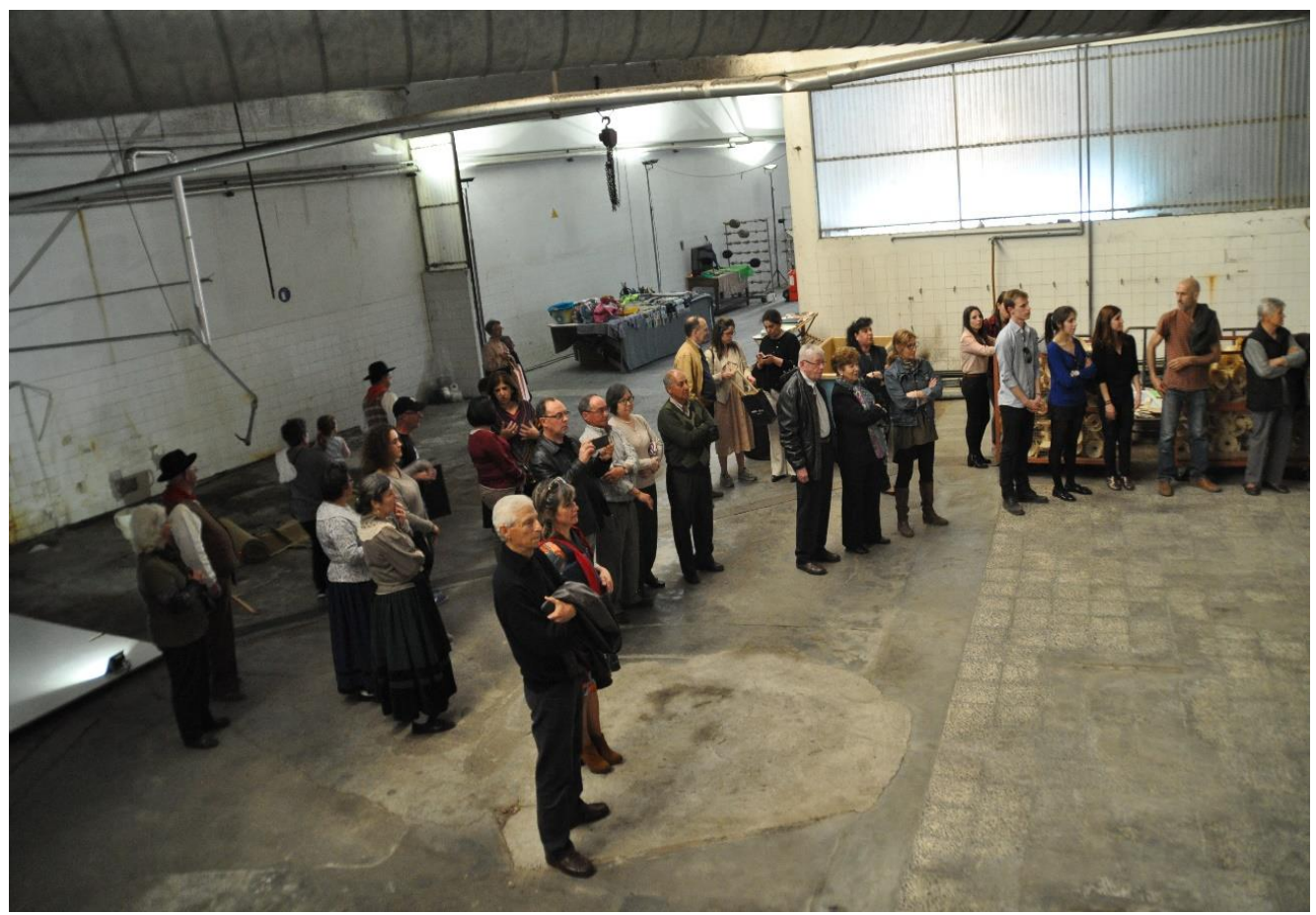

Figure 9. Creative Assault: Aspect of an Ecletic Public Source: Photo by Miguel Angelo Silva. 
We used the subjective perception as a central element in the relationship we wanted with the audience that participated in the Assault.

It was not our ambition to create a quiet or comfortable environment generating more or less contemplative attitudes. The ambition was the participation of the public in the Assault, although we knew that this inclusion should be qualified, and that was verified on almost all fronts that had been planned for this purpose. The audience, as varied as possible in their age groups or panoply of interests, became a dynamic element - thus the reading of the process, to some extent, depended on the movement of the visitor (Figures 8 and 9).

We have modified the impact on the senses caused by the place as material space becomes something else and, at a certain moment of the Assault, people freed their imagination, discovering something that only belongs to them, to their individual memory. All spaces have a particular significance, due to their history and their functions, whether these are domestic, collective or industrial spaces. It is in this sense that we have passed from a work based only on the memories triggered by a space enclosure, to another liberator of collective memories and, desirably, of wills of change.

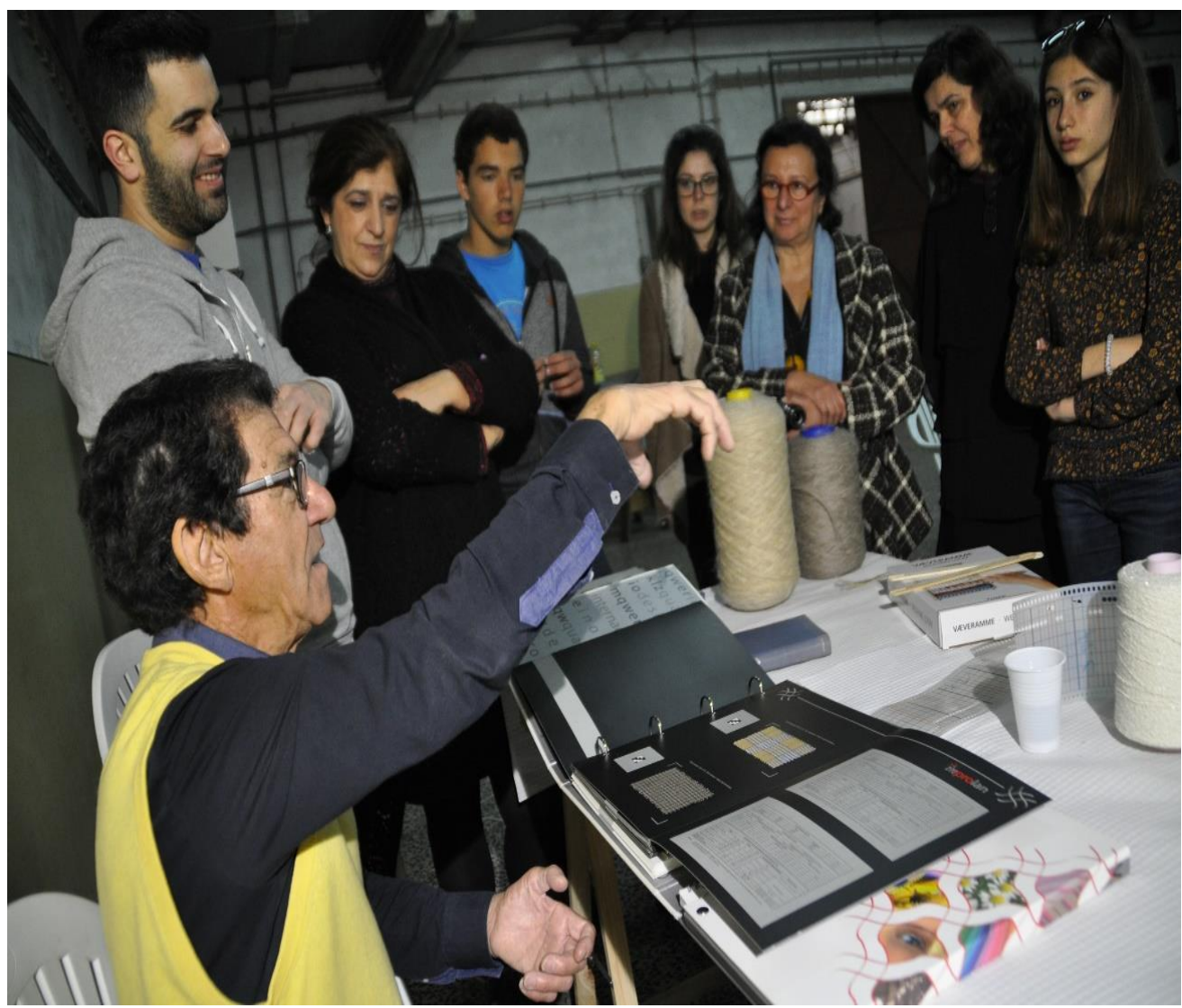

Figure 10. Creative Assault: Workshops and Demonstration of Products by Former Workers and Businessmen

Source: Photo by Miguel Angelo Silva. 


\section{Conclusions}

The idea of active musealization, an embryo of territorial marketing, may be able to promote sustainable investment, building a regenerative requalification of this stretch of landscape, restoring its character and continuity within the system where it is inserted and, in conclusion, setting the population through the rediscovery of its own identity.

This project, capable of giving market sense to new products born of industrial heritage, will also be able to build new socio-territorial meanings, through a process of territorial learning that combines training with experimentation and design (Figure 10). The dynamics born of this action could trigger an open educational process (in interaction with the outside), helping the regeneration of this place based on a sustainable community - in ways quite different from those in which it reached its apogee - within a hypertext society much more interconnected and integrated in the global scale. It is from this perspective that we intend to make a contribution to the re-humanization the place.

Whatever level of direct results obtained by this process is not statistically measurable. It was understood as the beginning of a journey, can be a catalyst for a develop movement that, centred on the integrated local governance, involves community members, local authorities, associations, schools and local businesses, as well as serves as an attracting point for "outsiders" into a more or less prolonged fixation, thus helping to the demographic rebalance.

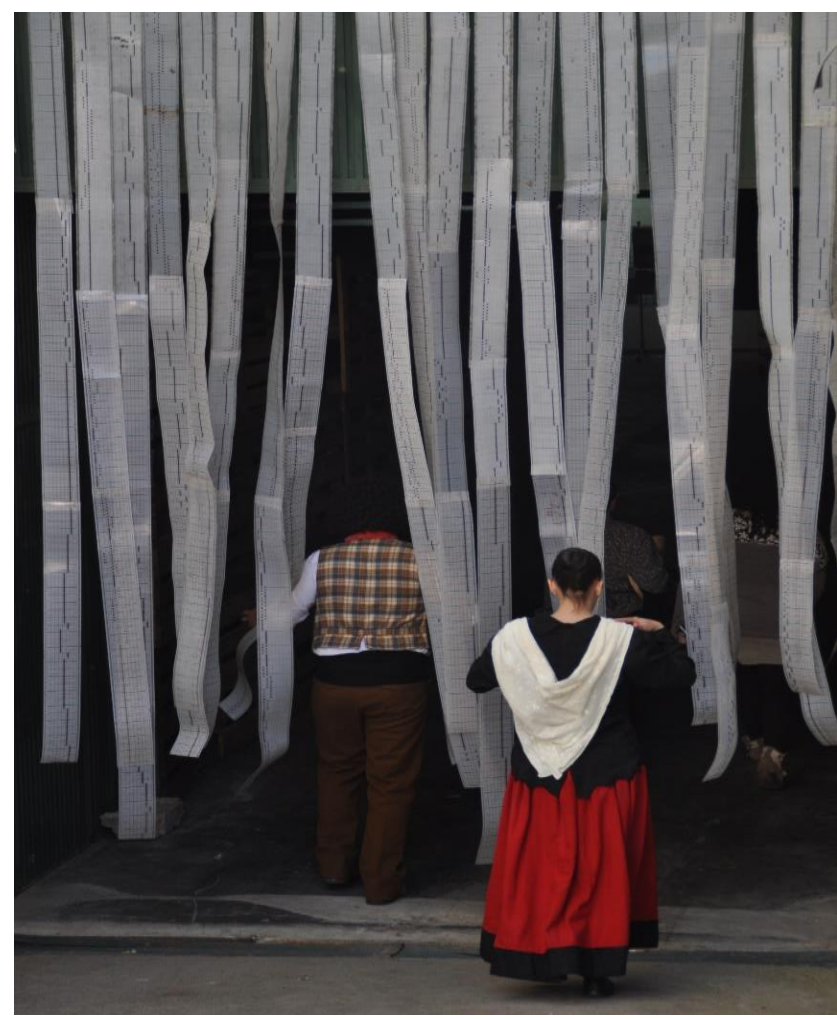

Figure 11. The Change through Art as a Wake-up System Source: Photo by Miguel Angelo Silva. 
The objectives were focused on the originated process of recalling, allowing brutally erased values to be remembered, and behave as levers of development and true generators of the cultural identity of each site.

Places Re-humanize for themselves, once they have faced their ghosts with the perspective of rebuilding the future! This process intends, only, to awake the will to do so, mobilizing the identity, memories and patrimonies of this community (Figure 11). That will be the true measurement of the success of this alert action.

\section{Acknowledgments}

This work is financed by National Funds through FCT - Foundation for Science and Technology, I.P., within the scope of Project UID/AUR/04026/2019.

\section{Bibliography}

Augé, M. Não Lugares - Introdução a uma antropologia da sobremodernidade. [No Places - Introduction to anthropology of supermodernity.] Lisbon: 90 Graus Editions, 2005.

Bergeron, L. "El patrimonio industrial, qué hacer?" [Industrial heritage, what to do?] In Patrimonio Industrial: Lugares de la Memoria. Gigon: Incuna, 2002, 11-16.

Cardoso, J. R. Subsídios para a história regional da Beira-Baixa-Castelo Branco na sua vida municipal. [Subsidies for the Regional History of Beira-Baixa-Castelo Branco in its municipal life.] Junta Provincial da Beira Baixa, 1944.

Domingues, Á. Vida no campo. [Life not field.] Lisboa: Dafne Editora, 2011.

Uriarte, I. Ría de Bilbao: la industria, fábrica del paisaje. [Ría de Bilbao: the industry, landscape factory.] Gigon: Abaco/CICEES, 2002, 109-116.

Varine, H. As raízes do futuro: O patrimônio a serviço do desenvolvimento local. [The roots of the future: heritage at the service of local development.] Porto Alegre: Medianiz, 2012. 